REVISTA DE DERECHO UNED, NÚM. 28, 2021

\title{
EL CONTROL DE CONVENCIONALIDAD FRENTE AL CONTROL CONCENTRADO CONSTITUCIONAL EN EL ECUADOR
}

\author{
THE CONTROL OF CONVENTIONALITY VERSUS THE \\ CONSTITUTIONAL CONCENTRATED CONTROL IN ECUADOR
}

Dra. Linda de las Mercedes Amancha Chiluisa

Docente de la Escuela de Jurisprudencia de la Pontificia Universidad Católica del Ecuador Sede Ambato - PUCESA

Sumario: I. Introducción. II. Planteamiento, definición y alcance del problema de investigación. II.1. El Control Constitucional en el Ecuador. II.2. Principio de Convencionalidad. II.3. Clases de Control de Convencionalidad. II.3.A. Control de Convencionalidad Concentrado. II.3.B. Control de Convencionalidad Difuso. II.3.C. Control de Convencionalidad Concreto y Abstracto. III. La Convencionalidad en el Ecuador. IV. Conclusiones y producto de investigación. v. Bibliografía. V.2. Referencias jurisprudenciales. V.3. Referencias normativas.

Resumen: El Principio de Convencionalidad nos permite examinar un adecuado cumplimiento de los tratados internacionales de todos los Estados Partes, miembros de la Convención Americana de Derechos Humanos, creados en San José de Costa Rica en noviembre de 1969. De esta forma es vital que las autoridades — sobre todo la judicial- cumpla estas disposiciones, tomando en consideración los artículos 1 y 2 de este instrumento.

El Ecuador requiere la búsqueda incesante de colacionar entre la legislación interna y los tratados internacionales corroborados hasta la actualidad, y aplicar de manera oportuna lo acentuado en los artículos anteriormente señalados. 
El Sistema de Control Concentrado de la Constitución en el Ecuador, se fundamenta en que solo debe existir un máximo organismo especializado y autónomo - Corte Constitucional - el cual tendrá la competencia para decidir en última y definitiva instancia todos los asuntos en materia constitucional, un control difuso. De esta manera los jueces o juezas de la Corte Constitucional, están facultados para efectuar un control de constitucionalidad de las normas infraconstitucionales invocadas dentro de un proceso judicial.

Palabras Clave: control de convencionalidad, estados parte, constitución, derechos humanos, convención americana, control concentrado.

Abstract: The Principle of Conventionality allows us to examine adequate compliance with the international treaties of all States Parties, members of the American Convention on Human Rights, created in San José, Costa Rica in November 1969. In this way it is vital that the authorities - especially the judicial authorities - comply with these provisions, according with the articles 1 and 2 of this instrument.

Ecuador requires the incessant search to collate domestic legislation and the international treaties that have been corroborated to date, and to apply in a timely manner the accentuated in the aforementioned articles.

The System of Concentrated Control of the Constitution in Ecuador is based on the fact that there must be only one a maximum specialized and autonomous must be only one - the Constitutional Court - which will have the competence to decide in the last and final instance all issues constitutional matters, a diffuse control. In this way, the judges of the Constitutional Court are empowered to control the he constitutionality of the infra-constitutional norms invoked within a judicial process.

Keywords: control of conventionality, states parties, constitution, human rights, american convention, concentrated control.

Recepción original: 28-06-2021

Aceptación original:14-09-2021

\section{INTRODUCCIÓN}

El Control de Convencionalidad es aquel que se ha ido edificando mediante la jurisprudencia que ha dictado la Corte Interamericana 
de los Derechos Humanos, y este ha ido evolucionando a través de los años. El principio de Convencionalidad nos permite comparar un adecuado cumplimiento de los tratados internacionales de todos los Estados Partes, miembros de la Convención Americana de Derechos Humanos, creados en San José de Costa Rica en noviembre de 1969. De esta forma es vital que las autoridades - sobre todo la judicial cumpla estas disposiciones, tomando en consideración los artículos 1 y 2 de este instrumento.

Las resoluciones de la Corte Interamericana de los Derechos $\mathrm{Hu}$ manos constituyen jurisprudencia vinculante que obliga a los Estados Parte que han ratificado la Convención Americana, por lo que resulta imperativo adecuar sus normas internas incluida la constitución para ser análogas y no contrarias a dicha norma internacional.

De esta manera, si se llegase a presentar una especie de duda o vacío legal por parte de los jueces ordinarios, ellos deben aplicar y ejercer un control difuso de convencionalidad, es decir, los órganos de la función judicial de los Estados Parte deben conocer a fondo y aplicar debidamente no solo el derecho constitucional, sino también el derecho internacional de los derechos humanos.

El Control Difuso de Convencionalidad es aquel que se encuentra ejercido por el poder judicial, como órganos encargados de administrar justicia, sin importar el grado, materia o especialidad a la que se dedique, con la finalidad de contrastar la norma interna en el caso concreto frente a la Convención Americana y la interpretación que la Corte Interamericana de Derechos Humanos le haya dado.

El sistema de Control Concentrado de la Constitución en el Ecuador, se fundamenta en que solo debe existir un máximo organismo especializado y autónomo - corte constitucional - el cual tendrá la competencia para decidir en última y definitiva instancia todos los asuntos en materia constitucional.

En este sentido, el estado ecuatoriano, en su búsqueda incesante por confrontar, entre la legislación interna y los tratados internacionales, requiere asentir en la actualidad una aplicación oportuna y correcta de lo acentuado anteriormente.

\section{PLANTEAMIENTO, DEFINICIÓN Y ALCANCE DEL PROBLEMA DE INVESTIGACIÓN}

El problema jurídico de la investigación radica en la contraposición que existe en la Constitución de la República al establecer solo 
el control concentrado de constitucionalidad en el Ecuador; a la par de la disposición de la Corte Interamericana de Derechos Humanos en la que se manifiesta la obligación que tienen los funcionarios judiciales de hacer el control de convencionalidad directamente, es decir un control difuso. Es por esta razón que se han investigado algunas fuentes primarias y secundarias para fundamentar el problema de investigación.

El origen del control de constitucionalidad data de Estados Unidos de Norteamérica en 1803. Marbury versus Madison es sin duda uno de los casos más famosos en el mundo, por cuanto su existencia crea un hito en el universo jurídico. Este caso se dio en Estados Unidos y marca el principio de un constitucionalismo moderno. (Bazán, 2009) menciona que el interés del caso va mucho más allá del constitucionalismo norteamericano y su principal debate se centra en el lugar que tiene la constitución dentro de un ordenamiento jurídico interno, esto es la supremacía constitucional.

De hecho, este caso es fundamental porque no solo establece el principio de supremacía constitucional, sino que también establece los mecanismos para aplicar la constitución de manera inmediata y directa, por todos los funcionarios judiciales, creando así el llamado control difuso de constitucionalidad (Bazán, 2009). Asimismo, es importante recalcar lo que sostiene (Herdegen, 2010), por cuanto este autor manifiesta que la jurisprudencia es una fuente del derecho hoy por hoy fundamental para los ordenamientos jurídicos internos de cada Estado, sobre todo en materia de derechos humanos.

De igual manera, Herdegen (2010) considera que es importante centrarse en el valor que tienen los mecanismos de protección de derechos humanos, y para esto se han creado un sinnúmero de figuras e instituciones jurídicas. Entre ellas destaca el control de constitucionalidad, así como el control de convencionalidad, mismos que han sido el resultado de largos análisis dentro del siglo XIX. Su creación se debe a la falta de protección de derechos que tenían los ciudadanos. Con el caso Marbury vs Madison se logró que los jueces cumplan y apliquen lo estipulado en la constitución, ya que estos al estar en primera línea con las personas tienen la obligación de respetarla y hacerla cumplir, bajo este parámetro el control difuso de constitucionalidad cobra fuerza y empieza a ser trasplantado en los demás sistemas jurídicos a nivel mundial. Hernández-Mendible (2015).

La trascendencia de este fallo dada en el año de 1803, en definitiva, causo toda una revolución del derecho constitucional, y que hasta la actualidad ha permitido a diferentes estados asentar una 
supremacía en la constitución, como la máxima ley fundamental que rige en todo país democrático. La constitución ante cualquier poder público del estado, incluido los jueces, quienes aplican las leyes deben de forma irrestricta hacerla respetar.

Gracias a los aportes realizados por Hans Kelsen, posterior a la constitución austriaca de 1920, nació la concepción en todo el mundo de confrontar las leyes expedidas por el congreso por medio de cortes que permitan un control constitucional de forma concentrada; así se crean en América Latina lo que hoy conocemos como: tribunales, cortes y salas constitucionales.

\section{II.1. El Control Constitucional en el Ecuador}

Como se ha mencionado en líneas anteriores, en el Ecuador se aplica el control concentrado de constitucionalidad; conforme lo estipula el mismo texto constitucional en su artículo 429. Este tipo de control establece que un órgano único e independiente, debe actuar de manera autónoma frente a las funciones del estado para que realice la interpretación de la carta constitucional. Básicamente la corte constitucional del Ecuador es aquel organismo encargado de la aplicación de la interpretación constitucional. De ahí se desprenden las diferentes jerarquías que existen para la correcta aplicación de justicia constitucional, esto es las funciones que tienen los jueces al momento de convertirse en jueces constitucionales.

La teoría kelseniana sostiene la idea de que la constitución necesita un organismo guardián independiente que vele por su efectivo cumplimiento y regule las atribuciones, garantías y autonomía del aparato jurisdiccional (Haro, 2004).

La coherencia que debe existir entre el ordenamiento jurídico y la constitución debe estar protegida y periódicamente controlada por un sistema creado para ello. Es por esta razón que, en el año 2008, los asambleístas constituyentes han decidido que el control ya no será difuso como la carta política de 1998 lo establecía, sino que más bien ahora toda esta competencia seria exclusiva de la nueva corte constitucional. Sin embargo, a criterio de la autora de esta investigación esta idea dentro del garantismo ecuatoriano trae consigo ciertas falencias o lagunas que los constituyentes omitieron resolver.

Al tratar de incorporar nuevos paradigmas dentro de la actual constitución se omitieron algunos presupuestos de vital importancia. Por cuanto, Baquerizo y Leuschner (2011)" al querer acaparar 
varias cuestiones y proteger todos los derechos no han logrado acaparar las vías de protección de los mismos, provocando una serie de falencias en cuanto a la protección de muchos derechos, al dejar en el limbo lo estipulado en la carta constitucional". (p. 44)

Actualmente en el Ecuador se efectúa el control concentrado para evitar que existan diferentes fallos desde las ópticas de los jueces de instancia en los casos judiciales, de modo que tengan las mismas características y evitar un trato desigual ante la constitución por los distintos órganos jurisdiccionales. El control concentrado de constitucionalidad permite garantizar la uniformidad de los fallos en materia constitucional. Su principal característica es ser vinculante y, o, erga omnes. Es decir, rige para todos los casos análogos a desarrollarse. La corte constitucional en sus fallos ha establecido que en nuestro país existe expresamente el control concentrado de constitucionalidad a raíz de la Sentencia N ${ }^{\circ} 001-13-S C N-C C$ (2013).

El control concentrado de constitucionalidad propende un control absoluto ante cualquier otra ley expedida en el territorio ecuatoriano. No da paso a que se llegue a presentar ambigüedad entre normas; ya que se le otorga la facultad absoluta a la corte constitucional para que ésta se pronuncie ante cualquier situación de duda entre alguna ley ordinaria adversa a Constitución, que los jueces de instancia pudiesen llegar a tener. Ahora bien, como ya lo han expresado Brewer-Carías y Santofimio Gamboa (2013), si este control concentrado no está bien encaminado, y quienes pertenecen a la corte constitucional no poseen su independencia de los poderes del estado, podría verse trastocado el efecto de dicho control por gobiernos de turno, en el fin para el cual esa corte constitucional fue designada.

\section{II.2. Principio de Convencionalidad}

Aguilar, G. (2013). El control de convencionalidad: análisis en derecho comparado. Revista Direito GV, Tomo 9 (N.2), págs. 721-754: "El control de convencionalidad es el control realizado por un juez nacional acerca de la conformidad del derecho estatal con los tratados y acuerdos internacionales. Uno de sus fines es blindar o escudar al Estado de potenciales demandas ante la jurisdicción internacional por incumplimiento o violación de dichos acuerdos o tratados internacionales. El juez nacional se convierte así en el juez de la convencionalidad en el derecho interno".

La Corte Interamericana de Derechos Humanos (CIDH) ha desarrollado suficiente jurisprudencia respecto del principio de convencio- 
nalidad. Sin embargo, éste tiene como origen en el Caso Trabajadores Cesados del Congreso (Aguado Alfaro y otros) vs. Perú. Sentencia de 24 de noviembre CIDH. (2006). En el cual la CIDH ha determinado que su tarea es verificar la actuación de los estados respecto de la aplicación de los instrumentos internacionales que forman parte del bloque de constitucionalidad (especialmente la Convención Americana de Derechos Humanos), tal como estos han sido adecuados en su normativa interna. Todo este análisis y estudio tiene como único propósito asegurar que los derechos fundamentales se encuentren garantizados y sean justiciables en cada uno de los Estados Partes. Por esta razón se ha determinado taxativamente lo siguiente:

[...] Cuando un Estado ha ratificado un tratado internacional como la Convención Americana, sus jueces también están sometidos a ella, lo que les obliga a velar porque el efecto útil de la Convención no se vea mermado o anulado por la aplicación de leyes contrarias a sus disposiciones, objeto y fin. En otras palabras, los órganos del Poder Judicial deben ejercer no sólo un control de constitucionalidad, sino también "de convencionalidad" ex officio entre las normas internas y la Convención Americana, evidentemente en el marco de sus respectivas competencias y de las regulaciones procesales correspondientes. Esta función no debe quedar limitada exclusivamente por las manifestaciones o actos de los accionantes en cada caso concreto, aunque tampoco implica que ese control deba ejercerse siempre, sin considerar otros presupuestos formales y materiales de admisibilidad y procedencia de ese tipo de acciones. (Caso Trabajadores Cesados del Congreso Aguado Álvaro y otros vs Perú, 2006, p.128).

Es por tal razón que la corte constitucional permite el control difuso de convencionalidad, al ser este un punto contrapuesto con la constitución ecuatoriana cae preguntarse por qué entonces hay esta antinomia. Al respecto, por su parte, habla de un - "control judicial interno de convencionalidad" y menciona que esta clase de control interno es un mecanismo por medio del cual los funcionarios jurisdiccionales de cada Estado Partes van haciendo un cotejamiento o revisión del precepto normativo interno y los instrumentos supranacionales, con el único fin de velar por los derechos fundamentales de las personas derivados de los instrumentos del bloque, tarea que luego será revisada por la misma CIDH en algún caso concreto.

Dentro de la Convención Americana de Derechos Humanos - en su artículo segundo, se menciona el principio de convencionalidad en líneas generales, sin embargo, cabe resaltar que sus definiciones y alcances se han logrado a través del desarrollo jurisprudencial de este órgano. Siguiendo con lo manifestado, el artículo 2 de la Convención; (1969) sostiene lo siguiente: 
Si en el ejercicio de los derechos y libertades mencionados en el artículo 1 no estuviere ya garantizado por disposiciones legislativas o de otro carácter, los Estados Partes se comprometen a adoptar, con arreglo a sus procedimientos constitucionales y a las disposiciones de esta Convención, las medidas legislativas o de otro carácter que fueren necesarias para hacer efectivos tales derechos y libertades (CADH, 1969, Art.2)

Como se mencionó en el párrafo anterior, la Convención ya posee dentro de sí un artículo destinado al garantizar el principio de convencionalidad, solo que ahora hace falta encontrar la vía más idónea y efectiva de realizar su control pues como ya se ha visto no sería prudente esperar la vulneración de un derecho para revisar si en efecto el Estado cumplió o no con lo estipulado.

El control de convencionalidad a palabras mismas de la Corte IDH, en la Opinión Consultiva OC-21/14 significa que los jueces son quienes tienen que realizar el control de convencionalidad interno, para lo cual no solo observarán la Convención, sino también la interpretación que de ella ha hecho la propia Corte. (Corte IDH,19 de agosto del 2014). Empero el alcance que tiene este control no está direccionado únicamente para autoridades jurisdiccionales, sino que también para todas aquellas autoridades del estado. Cuestión a la cual sumó la obligación de los jueces de realizar este control de oficio. (Caso Cabrera García y Montiel Flores vs. México, 2010).

Pues como dice el resumen: Este artículo explora las razones por las que los Estados Partes tienen el deber de incorporar los lineamientos establecidos en esta opinión consultiva. Entre estos motivos, por un lado, están la obligación de las autoridades estatales de realizar un control de convencionalidad, y los principios de igualdad y no discriminación como partes consustanciales del ius cogens. León, M. (2019). La fuerza vinculante de la OC-24/17 "Identidad de género e igualdad y no discriminación a parejas del mismo sexo" para el Estado ecuatoriano. FORO: Revista de Derecho, (32), págs. 43-60.

\section{II.3. Clases de Control de Convencionalidad}

Al control de convencionalidad es posible clasificarlo en control de convencionalidad concentrado y control de convencionalidad difuso. 


\section{II.3.A. Control de Convencionalidad Concentrado}

Villacís (2018) indica que el control de convencionalidad concentrando o en sede internacional, debe realizarlo de forma exclusiva la Corte IDH, dentro del ámbito del Sistema Interamericano de Derechos Humanos.

En virtud de este control de convencionalidad concentrado, la Corte IDH se encarga de revisar aquellos actos del estado que no sean contrarios a la Convención Americana, instaurando, en casos de contradicción, la responsabilidad del Estado en cuestión y no solo del órgano responsable, en este caso la Corte tiene la posibilidad de declarar que el acto es contrario a la convención y podrá solicitar su modificación o reparación, como lo indica Sagüez (2014).

El control de convencionalidad que instaura la Corte IDH, en resumen, se basa en que, de acuerdo a su facultad de competencia contenciosa, puede determinar la responsabilidad internacional del Estado, por la violación de los derechos que se hallan consagrados ya sea en el Convención Americana como en otros instrumentos conexos. Villacís (2018).

\section{II.3.B. Control de Convencionalidad Difuso}

El control de convencionalidad difuso, es aquel que se da por medio de los estados a través de las diferentes autoridades y dependerá en el ámbito de sus competencias. Luchietti, A. (2008). Los jueces y algunos caminos del control de convencionalidad. México: Estudios Constitucionales.

El control difuso proviene directamente del ámbito de competencia de la CIDH, la misma que permite incorporar en el ámbito de competencia de cada uno de los Estados parte de la Convención Americana. Castilla, K. (2014). Control de convencionalidad interamericano: una mera aplicación del derecho internacional. Derecho del Estado, ( $\left.\mathrm{N}^{\circ} 33\right)$, págs. 149-172. Las disposiciones de la Convención forman parte del derecho interno, a través de las cláusulas constitucionales de recepción que obligan a los Estados a ajustar su normativa interna al ordenamiento jurídico convencional.

Para la aplicación del control de convencionalidad difuso, el juez posee algunas alternativas, y es el de poder aplicar la norma interna, pero adecuándola al contenido de la Convención. Este control local en sede judicial, se debe agregar el control difuso que, por criterio de 
la propia CIDH, deben hacer todos los órganos de la administración pública, es decir todos los órganos públicos tienen el deber de velar, en el ejercicio de sus competencias se observe y respete las normas de la Convención. Villacís (2018).

\section{II.3.C. Control de Convencionalidad Concreto y Abstracto}

Esta clasificación nos permite observar al objeto sobre el cual debe ejercerse el control de convencionalidad, es por esta razón que se le puede clasificar en concreto y abstracto.

Para Villacís, H. (2018). El control de convencionalidad y su aplicación en Ecuador. Revista San Gregorio, (N²6), págs. 84-91, las dos formas permiten realizar el control respecto a las normas o leyes que se han aplicado a casos específicos y que por ello han dado origen a una violación al orden jurídico vigente.

El control abstracto permite que la CIDH pueda realizar un examen sobre aquellas normas o leyes, que, sin haber sido aplicadas en casos específicos, por su simple configuración se presume una violación al marco jurídico convencional.

Este control se originó gracias al voto en contra emitido por el juez Cançado Trindade, en el caso El Amparo vs. Venezuela, la Corte resolvió que no iba a conocer este caso, en vista de que la ley que había sido impugnada no se había aplicado a ningún caso en particular; más el voto en contra manifestaba:

[...] la propia existencia de una disposición legal puede per se crear una situación que afecta directamente los derechos protegidos por la Convención Americana. Una ley puede ciertamente violar estos derechos en razón de su propia existencia, y, en la ausencia de una medida de aplicación o ejecución, por la amenaza real a las personas representada por la situación creada por dicha ley. Corte IDH. (1996). Caso El Amparo Vs. Venezuela. Sentencia de 14 de septiembre.

En este sentido, no hace falta que la norma se aplique para determinar que ésta es contraria a los derechos humanos, Nogueira, H. (2013). El control de convencionalidad y el diálogo interjurisdiccional entre tribunales nacionales y Corte Iberoamericana de Derechos Humanos. Revista de derecho constitucional europeo, ( $\left.{ }^{\circ} .19\right)$, págs. 221-270, menciona que, al existir una lesión de los derechos, se estaría dejando a un lado el deber de prevención, y por ende al control abstracto, ya que una ley podría ser contraria a la Convención por su propia existencia. 


\section{LA CONVENCIONALIDAD EN EL ECUADOR}

El marco constitucional del Ecuador es muy amplio y ha concentrado de manera muy especial todo el ordenamiento jurídico internacional en su normativa interna, tal es así que dentro de la constitución de la república se han contemplado principios como el de supraconstitucionalidad, de clausula abierta, que lo que ha hecho es garantizar sin discriminación alguna el efectivo goce de los derechos establecidos en la constitución y en los instrumentos internacionales, Hernández-Mendible (2015).

Así mismo el principio de aplicación directa de las normas constitucionales contemplado también en la norma suprema artículo 11, contiene también aquellas expresadas en instrumentos internacionales de derechos humanos. Por otra parte, ya en el ámbito de garantías jurisdiccionales, la acción por incumplimiento se erige como un mecanismo de exigibilidad de las sentencias o informes de organismos internacionales de derechos humanos. Hasta llegar al artículo 424 en donde la propia carta constitucional contempla el principio de supremacía constitucional, y es este mismo texto quien faculta a los tratados internacionales ir por encima de ella en el caso de mayor protección a los derechos humanos.

Bajo este contexto, y en virtud de lo expresado por Gutiérrez, (2016), el control de convencionalidad que les compete realizar a las instituciones públicas ecuatorianas, tanto en sede jurisdiccional como no jurisdiccional, es el control difuso de convencionalidad, como una responsabilidad emanada no solo de los compromisos internacionales adquiridos por el Estado ecuatoriano, sino como un deber de orden constitucional. Lo que nos queda por dilucidar es cómo se ejerce ese control en Ecuador (Sentencia No. 001-13-SCN-CC).

Al tener únicamente el control concentrado de constitucionalidad en Ecuador se entendería que los jueces no pueden hacer el ejercicio de revisión de la convencionalidad por sí solos, pero esto no es del todo cierto ya que en la práctica los jueces lo harán de la misma forma en que realizan el control de constitucionalidad, por lo tanto, lo que no está permitido hacer es expulsar o inaplicar una norma convencional del ordenamiento jurídico, pues para ello tienen el mecanismo de consulta de norma, establecido en la constitución, en su artículo 428. (Sentencia N. 055-SEP-CC,2010).

Por lo tanto, a palabras de Sagüez (2014) la facultad que posee el juez ecuatoriano es la de la interpretación conforme, que, además, 
constituye un principio transversal dentro de la constitución, a propósito de la masiva incorporación del orden jurídico internacional. Por lo que, el trabajo del juez, en virtud del control de convencionalidad será interpretar la norma, de la manera en que más se ajuste a la Convención y demás instrumentos internacionales de Derechos Humanos, labor que se hace extensiva a todos los órganos del Estado, en virtud de la extensión del control difuso que hemos explicado.

\section{CONCLUSIONES Y PRODUCTO DE LA INVESTIGACIÓN}

Podemos concluir como resultado de la investigación realizada que el control de convencionalidad ha venido aplicándose de manera oportuna por la CIDH, esto significa que los tratados internacionales al igual que la constitución en materia de derechos humanos, tienen un rol fundamental en cuanto al principio pro homine y por lo tanto se debe aplicar si excepción por parte de los jueces y juezas del Ecuador.

Los jueces y juezas nacionales, deberían solicitar la incorporación de la convencionalidad como parte de los principios rectores y disposiciones fundamentales, contenido en el código orgánico de la función judicial; de esta manera podrán ejercer una especie de control de convencionalidad, comparando la norma interna frente a la norma internacional, en vista de que los jueces ecuatorianos están sometidos al imperio de la normativa nacional como aquellas normas establecidas en los tratados internacionales y ratificados por el estado.

El control concentrado que existe en la actual constitución ecuatoriana, y con los actuales acontecimientos jurídicos y políticos que nos encontramos viviendo, deja mucho a la duda el creer que exista una total independencia en los poderes del estado, y por ende en la corte constitucional, por lo tanto creemos que debe darse una urgente modificación del control concentrado, y permitir aplicar de forma oportuna el control de convencionalidad a todos los jueces y juezas de cualquier instancia, quienes están en la obligación de aplicarlo, en defensa de los derechos humanos. 


\section{BIBLIOGRAFÍA}

\section{V.1. Referencias bibliograficas}

Aguilar, G. (2013). El control de convencionalidad: análisis en derecho comparado. Revista Direito GV, Tomo 9 (N.2), págs. 721-754.

Baquerizo Minuche, J., \& Leucshner, E. (2011). Sobre Neoconstitucionalismo, principios y ponderación. Guayaquil: EDILEX S.A.

BAZÁn, V. (2009). En torno a la justicia constitucional latinoamericana en los albores del Siglo XXI. En E. Alvarez Miranda, \& C. Mesías Ramírez, Constitución y Proceso (págs. 21-51). Lima: Jurista Editores E.I.R.L.

Brewer-Carías, A., \& Santofimio Gamboa, J. (2013). Control de Convencionalidad y Responsabilidad.

CASTILla, K. (2014). Control de convencionalidad interamericano: una mera aplicación del derecho internacional. Derecho del Estado, $\left(\mathrm{N}^{\circ}\right.$ 33), págs. 149-172

GutiérRez, L. (2016). Control de Constitucionalidad y control de convencionalidad: interacción, confusión y autonomía. Revista Instituto Interamericano de Derechos Humanos, 239-264.

HARO, R. (2004). El control de constitucionalidad comparado y el rol paradigmático de las cortes y tribunales constitucionales. En J. Woischnik, Anuario de Derecho Constitucional Latinoamericano (págs. 41-74). Montevideo: Konrad Adenauer.

Herdegen, M. (2010). La internacionalización del orden constitucional. En G. Elsner, Anuario de Derecho Constitucional Latinoamericano 2010 (págs. 72-81). Montevideo: Konrad Adenauer.

HERNÁNDEZ-MENDIBLE, V. (2015). El control de convencionalidad como expresión del control de constitucionalidad: originalidad y desaciertos. Revista de Investigações Constitucionais Vol.2, 137-168.

LEón, M. (2019). La fuerza vinculante de la OC-24/17 "Identidad de género e igualdad y no discriminación a parejas del mismo sexo" para el Estado ecuatoriano. FORO: Revista de Derecho, (32), págs. 43-60.

LuChiETti, A. (2008). Los jueces y algunos caminos del control de convencionalidad. México: Estudios Constitucionales.

NogueIRA, H. (2013). El control de convencionalidad y el diálogo interjurisdiccional entre tribunales nacionales y Corte Iberoamericana 
de Derechos Humanos. Revista de derecho constitucional europeo, ( $\left.{ }^{\circ} .19\right)$, págs. 221-270.

SAGÜEZ, N. P. (2014). Nuevas fronteras del control de convencionalidad: el reciclaje del derecho nacional y el control legisferante de convencionalidad. Revista de Investigações Constitucionais Vol. 1, 23-32.

VILlacís, H. (2018). El control de convencionalidad y su aplicación en Ecuador. Revista San Gregorio. págs. 85-89.

\section{V.2. Referencias jurisprudenciales}

Opinión Consultiva OC-21/14. (Corte IDH,19 de agosto del 2014).

Corte IDH. (2010). Caso Cabrera García y Montiel Flores Vs. México. Sentencia 26 de noviembre.

Corte IDH. (2006). Caso Trabajadores Cesados del Congreso (Aguado Alfaro y otros) vs. Perú. Sentencia de 24 de noviembre.

Corte IDH. (1996). Caso El Amparo Vs. Venezuela. Sentencia de 14 de septiembre.

Sentencia N. 055-SEP-CC. (Corte Constitucional del Ecuador, para el período de transición. 18 de noviembre de 2010).

Sentencia No. 001-13-SCN-CC (Corte Constitucional del Ecuador. 13 de febrero de 2013)

\section{V.3. Referencias normativas}

Constitución de la República del Ecuador/ Registro Oficial 449, 20 de octubre (2008).

Convención Americana de Derechos Humanos, San José, 22 de noviembre (1969). 